\title{
A PERCEPÇÃO DE ALUNOS DE GRADUAÇÃO EM CIÊNCIAS CONTÁBEIS ACERCA DAS COMPETÊNCIAS DO PROFISSIONAL CONTÁBIL
}

\section{THE PERCEPTION OF ACCOUNTING STUDENTS ABOUT THE COMPETENCES OF THE ACCOUNTANT}

\author{
Gustavo Santos Delfino* \\ Victor Amaral Floriano** \\ Carlos Eduardo Araújo da Silva*** \\ Zilton Bartolomeu Martins****
}

\begin{abstract}
RESUMO
Este estudo teve como objetivo analisar a percepção de alunos de graduação em Ciências Contábeis acerca das competências do profissional contábil. Conforme a metodologia, esta pesquisa classifica-se como quantitativa, em relação à abordagem, descritiva, quanto aos objetivos e no que diz respeito aos procedimentos, trata-se de uma pesquisa de levantamento. Como instrumento de coleta de dados, aplicou-se um questionário, baseado nas pesquisas de Faotto e Jung (2018), Wollinger, Martins e Marinho (2018), Moura e Lima Filho (2019) e Silva et al. (2020), contendo 11 (onze) questões fechadas, validado por professores da área e aplicado por meio eletrônico no período entre agosto e setembro de 2020. A população deste artigo foi de 335 alunos matriculados em 2020/2 nos cursos de Ciências Contábeis de uma universidade comunitária de Santa Catarina, resultando em uma amostra de 111 respondentes, que representa 33,13\% da população. Os dados coletados foram tabulados por meio do Google Formulários® e utilizou-se como técnica de análise de dados, a estatística descritiva, segundo a distribuição de frequência relativa. Como principais resultados, pode-se observar que a percepção dos graduandos acerca das competências do profissional contábil vai ao encontro do que estabelece a Resolução CNE/CES 10, de 16 de dezembro de 2004, que instituiu as diretrizes curriculares nacionais para o curso de graduação em Ciências Contábeis. Também se verificou que o curso de Ciências Contábeis prepara seus discentes de maneira adequada, demonstrando quais habilidades e competências devem desenvolver e aprimorar, com o objetivo de se tornarem profissionais contábeis aptos a atuar no mercado de trabalho em benefício da sociedade como um todo.
\end{abstract}

Palavras-Chave: Competências; Profissional Contábil; Graduação; Ciências Contábeis.

\section{ABSTRACT}

This study aimed to analyze the perception accounting students about the competences of the accountant. According to the methodology, this research is classified as quantitative, in relation to the approach, descriptive, as to the objectives and with regard to the procedures, it is a survey research. As a data collection instrument, a questionnaire was applied, based on research by Faotto and Jung (2018), Wollinger, Martins and Marinho (2018), Moura and Lima Filho (2019) and Silva et al. (2020), containing 11 (eleven) closed questions, validated by professors in the area and applied electronically in the period between August and September 2020. The population of this article was 335 students enrolled in 2020/2 in accounting of the community university in Santa Catarina, resulting in a sample of 111 respondents, representing $33.13 \%$ of the population. The collected data were tabulated using Google Forms ${ }^{\circledR}$ and descriptive statistics were used as a data

\footnotetext{
* UNIVALI — Universidade do Vale do Itajaí. E-mail: gustavodelfino9@ gmail.com

** UNIVALI — Universidade do Vale do Itajaí. E-mail: victoramaralfloriano@ hotmail.com

*** UNIVALI — Universidade do Vale do Itajaí. E-mail: araujocarloseduardo57@ gmail.com

**** UNIVALI — Universidade do Vale do Itajaí. E-mail: araujocarloseduardo57@gmail.com

Revista Eletrônica do Alto Vale do Itajaí - REAVI, v.10, nº 16, p. 001-017, ago. 2021.
} 
analysis technique, according to the distribution of relative frequency. As main results, it can be observed that the perception of students about the competences of the accountant is in line with the provisions of Resolution CNE/CES 10, of December 16, 2004, which established the national curriculum guidelines for the accounting course. It was also found that the accounting course prepares its students adequately, demonstrating which skills and competencies they should develop and improve, with the aim of becoming accountants able to work in the labor market for the benefit of society as a whole.

Keywords: Competences; Accountant; University Graduate; Accounting.

Data de submissão: 10 de junho de 2021.

Data de aprovação: 28 de julho de 2021.

Disponibilidade: DOI 10.5965/2316419010152021001

\section{INTRODUÇÃO}

A ênfase dada à contabilidade e ao profissional contábil tem mudado nos últimos anos. Ao adotar as normas internacionais de contabilidade, o Brasil alterou não só a legislação e procedimentos contábeis, mas também a forma de atuação dos contadores (REIS et al., 2015). Além disto, as organizações se tornaram mais competitivas e dinâmicas com o avanço da globalização e da tecnologia. Desta maneira, a informação contábil passou a ter um papel de extrema relevância, já que serve de base para a tomada de decisão dos administradores (FAOTTO; JUNG, 2018).

Neste contexto, Alves et al. (2016) observam que o profissional contábil passou a ser exigido não só com seus conhecimentos técnicos, mas também pensamentos críticos e habilidades voltadas à gestão e ao empreendimento. Desta forma, observa-se que o contador, por ser provido de conhecimento e ferramentas de gestão advindos dos relatórios presentes na contabilidade, pode possuir uma visão ampla e qualificada da situação da empresa. Cabe destacar que Reis et al. (2015) enfatizam que as diretrizes curriculares instituídas pelo Conselho Nacional de Educação (CNE) de $n^{\circ} 10 / 2004$, propuseram às Instituições de Ensino Superior (IES), determinadas habilidades e competências para a formação do bacharel em Ciências Contábeis, com conhecimentos que abrangem desde a comunicação, até o desenvolvimento de sistemas de informações contábeis.

Com isto, Oliveira, Pizanni e Faria (2017) reforçam que os diversos desafios presentes no ambiente mercadológico, desafiam também o ambiente acadêmico ao desempenhar o seu papel como formador de profissionais aptos e capazes de interpretar fatos e criar soluções rápidas e inovadoras. O profissional contábil vem passando por uma constante agregação de competências e responsabilidades, pois, atualmente, é um profissional que detém formação com conhecimentos abrangentes, envolvendo dentro da área contábil, conhecimentos relacionados às áreas de Direito, Administração, Matemática, Economia, Finanças, entre outras.

Para Pereira (2017), a constituição de empresas sólidas é indispensável para o desenvolvimento da economia na medida em que estas conseguem pagar seus impostos, movimentar renda e empregos, porém, precisam de informação econômica e financeira de qualidade para a tomada de decisões de forma inteligente. Para suprir esta necessidade, o contador é o profissional mais qualificado, pois além de contribuir para o desenvolvimento da entidade, colabora para o desenvolvimento econômico-social como um todo. Desta forma, Moura e Lima Filho (2019) complementam que é de suma importância a constante atualização do contador no cenário atual, investindo em educação continuada. Além disto, há a necessidade de equilibrar os

Revista Eletrônica do Alto Vale do Itajaí - REAVI, v.10, nº 16, p. 001-017, ago. 2021. 
conteúdos curriculares das IES, às exigências do mercado, com o intuito que contribuam para o desenvolvimento de competências e formação de um profissional contábil apto para atuar em diversas áreas, de acordo com seu perfil e suas expectativas.

Nesta linha de pensamento, o presente artigo visa responder a seguinte pergunta de pesquisa: Qual a percepção de alunos de graduação em Ciências Contábeis acerca das competências do profissional contábil? O objetivo desta pesquisa é analisar a percepção de alunos de graduação em Ciências Contábeis acerca das competências do profissional contábil.

Como justificativa teórica, Adam, Cunha e Boff (2018) analisaram a produção científica nacional relacionada às competências do contador na perspectiva da universidade, do acadêmico e do mercado de trabalho e recomendam investigações que possam promover o entendimento da existência de alguma deficiência no processo de formação, de alguma ruptura entre o que é requerido pelo mercado de trabalho, daquilo que o meio acadêmico promove. Já Wollinger, Martins e Marinho (2018) analisaram a relação entre os estilos de aprendizagem e as competências individuais adquiridas, segundo a perspectiva do curso de graduação em Ciências Contábeis e propõem que a pesquisa seja replicada em outros cursos de Ciências Contábeis a fim de comparar os resultados obtidos.

Por fim, Silveira et al. (2019) aproximaram as competências profissionais requeridas para a atuação profissional com as exigidas no exame de certificação da profissão contábil e sugerem investigar qual a opinião de concluintes do curso de Ciências Contábeis sobre competências profissionais adquiridas e exigidas no exame de certificação.

Como justificativa empírica, este estudo pode contribuir para os discentes e docentes do curso de Ciências Contábeis, no sentido de proporcionar uma visão mais aprofundada acerca das principais e mais recorrentes competências do profissional contábil, possibilitando que seja ofertado pelos docentes um ensino mais efetivo na formação profissional de seus alunos e também servir como facilitador para os discentes definirem com maior segurança sua área de especialização, com base nos requisitos do mercado de trabalho.

Este artigo contém, além desta introdução, uma fundamentação teórica sobre o tema, os procedimentos metodológicos que foram utilizados para a execução deste estudo, a análise dos resultados encontrados e, por último, as considerações finais, seguido das referências.

\section{FUNDAMENTAÇÃO TEÓRICA}

Nesta fundamentação teórica, são abordados os assuntos relativos à profissão e o profissional contábil, competências do profissional contábil e os estudos anteriores sobre o tema.

\subsection{A PROFISSÃO E O PROFISSIONAL CONTÁBIL}

O profissional de contabilidade tem contribuído tanto para o crescimento, quanto para o desenvolvimento econômico do país, no momento que prepara as demonstrações contábeis e leva as informações para os gestores poderem tomar as decisões nas organizações. Ao utilizar suas ferramentas de contabilidade, pode alavancar o desenvolvimento econômico, seguindo seus conteúdos teóricos, técnicos e práticos, para aumentar o sucesso das empresas (PEREIRA, 2017).

No Brasil, as práticas contábeis comerciais e governamentais são existentes desde o período colonial, porém, a primeira regulamentação da profissão contábil veio em 1770, dando privilégios aos guarda-livros formados nas aulas de comércio, estabelecendo sua matrícula na Junta Comercial de Lisboa (SILVA, 2015). Entretanto, Araujo, Pureza e Silva (2016) enfatizam que somente com o advento da Lei 6.404/1976, que houveram alterações substanciais na estrutura contábil em relação à estrutura normativa existente da época. Isto era condizente com o crescimento do mercado de capitais brasileiro, como tentativa de criar uma estrutura legal de

Revista Eletrônica do Alto Vale do Itajaí - REAVI, v.10, nº 16, p. 001-017, ago. 2021. 
negócios para o país e a necessidade de atualizar o arcabouço legal, face às mudanças ocorridas no ambiente externo.

Souza et al. (2018) comentam que a contabilidade possui ferramentas que oferecem poderosas armas para a manutenção de uma empresa, oferecendo boas informações para as possíveis decisões que devam ser tomadas. A partir dos relatórios emitidos pela contabilidade, é possível verificar como a saúde da empresa está e, a partir daí, apresentar as providências cabíveis diante do quadro empresarial em que se encontra.

Para manterem-se atuantes e assegurarem o sucesso nos negócios, é fundamental para as empresas promoverem seu desenvolvimento organizacional. É nesta etapa que surge a necessidade do envolvimento de um profissional da área contábil, auxiliando os gestores na melhor compreensão da execução dos processos da empresa (OLIVEIRA; BENETTI, 2016).

Neste contexto, Faotto e Jung (2018) observam que a contabilidade evoluiu ao longo do tempo, devido ao desenvolvimento econômico, ao avanço tecnológico e à globalização, com o intuito de melhorar as informações fornecidas aos seus usuários e atender às exigências do mercado. Os autores ainda salientam que em virtude destas situações, percebeu-se uma mudança no mercado de trabalho do profissional contábil, que hoje carece de outras habilidades e competências, além do conhecimento técnico.

Quanto aos hábitos e rotinas que estão presentes tanto em procedimentos de gestores, como por contadores, identifica-se uma certa semelhança aos procedimentos que envolvem um contato mensal entre organização e o profissional. Evidenciou-se que mensalmente, há um repasse de informações da empresa para que sejam realizados os procedimentos contábeis por seus responsáveis. Nestes procedimentos, é possível detectar que as rotinas e hábitos dentre diferentes profissionais, são, de certa forma, semelhantes (GOMES; WALTER; SOUTES, 2019).

Assim, estas informações poderão ser aperfeiçoadas e aprimoradas por meio do conhecimento. Destaca-se que a especialização dos profissionais acontece principalmente por intermédio de cursos de especialização, enquanto a forma de manter-se atualizados se dá por meio da leitura de periódicos da área e cursos particulares (MARCHALEK et al., 2016).

Gomes, Walter e Soutes (2019) deixam claro que ao realizarem um estudo sobre o perfil dos contadores, durante a análise das falas dos gestores entrevistados, a maioria acredita que seus profissionais estão dentro de um padrão, não conseguindo citar diferenças quando comparados com outros contadores. Um gestor apresentou a informação de considerar o profissionalismo e seriedade de sua contadora como um diferencial.

Desta forma, Oliveira, Pizanni e Faria (2017) deixam claro que o profissional contábil é uma peça integrante do mundo dos negócios, sendo exigida uma postura que garanta ações e decisões bem delimitadas, embasadas em conhecimentos que reflitam diversas esferas do saber, sendo a busca por contínuo aprendizado, uma necessidade básica para sua estadia no mercado de trabalho. Com isto, pode-se considerar que a formação acadêmica é ponto de partida para o desenvolvimento deste perfil exigido tanto pela sociedade, quanto pelas organizações.

\subsection{COMPETÊNCIAS DO PROFISSIONAL CONTÁBIL}

O perfil do profissional contábil mudou, pois cada vez mais, novas competências são requeridas deste bacharel. As atribuições e responsabilidades que até então determinavam suas funções e posições nas empresas, mudaram. Sua participação no processo decisório passou a exigir-lhe uma visão mais ampla dos cenários em que a empresa se insere, fazendo com que o seu trabalho deixe de ser apenas uma ferramenta operacional de transcrição de valores e resultados contábeis, criando, assim, a necessidade do profissional contábil assumir também funções gerenciais. Portanto, o empreendedorismo, dentre outros, passa a ser um fator relevante às qualificações e competências gerenciais deste "novo" profissional (MADRUGA; COLOSSI;

Revista Eletrônica do Alto Vale do Itajaí - REAVI, v.10, nº 16, p. 001-017, ago. 2021. 
BIAZUS, 2016).

Conforme a Resolução CNE/CES 10, de 16 de dezembro de 2004, que instituiu as diretrizes curriculares nacionais para o curso de graduação em Ciências Contábeis, o curso deve possibilitar uma formação profissional que revele, dentre outras, as competências e habilidades em demonstrar visão sistêmica e interdisciplinar da atividade contábil (CONSELHO NACIONAL DE EDUCAÇÃ̃, 2004). A seguir, apresenta-se o Quadro 1, onde são descritas as competências conforme a Resolução.

Quadro 1 - Competências conforme Resolução n 10 do Conselho Nacional de Educação (2004)

\begin{tabular}{|c|c|}
\hline Artigo & Competências \\
\hline \multirow{3}{*}{$\begin{array}{l}\text { Art. } 3^{\circ} \mathrm{O} \text { curso de } \\
\text { graduação em } \\
\text { Ciências Contábeis } \\
\text { deve ensejar } \\
\text { condições para que } \\
\text { o futuro } \\
\text { contabilista seja } \\
\text { capacitado a: }\end{array}$} & $\begin{array}{l}\text { I - compreender as questões científicas, técnicas, sociais, econômicas e financeiras, em âmbito } \\
\text { nacional e internacional e nos diferentes modelos de organização; }\end{array}$ \\
\hline & $\begin{array}{l}\text { II - apresentar pleno domínio das responsabilidades funcionais envolvendo apurações, } \\
\text { auditorias, perícias, arbitragens, noções de atividades atuariais e de quantificações de } \\
\text { informações financeiras, patrimoniais e governamentais, com a plena utilização de inovações } \\
\text { tecnológicas; }\end{array}$ \\
\hline & $\begin{array}{l}\text { III - revelar capacidade crítico-analítica de avaliação, quanto às implicações organizacionais } \\
\text { com o advento da tecnologia da informação. }\end{array}$ \\
\hline \multirow{8}{*}{$\begin{array}{l}\text { Art. } 4^{\circ} \mathrm{O} \text { curso de } \\
\text { graduação em } \\
\text { Ciências Contábeis } \\
\text { deve possibilitar } \\
\text { formação } \\
\text { profissional que } \\
\text { revele, pelo menos, } \\
\text { as seguintes } \\
\text { competências e } \\
\text { habilidades: }\end{array}$} & I - utilizar adequadamente a terminologia e a linguagem das Ciências Contábeis e Atuariais; \\
\hline & II - demonstrar visão sistêmica e interdisciplinar da atividade contábil; \\
\hline & $\begin{array}{l}\text { III - elaborar pareceres e relatórios que contribuam para o desempenho } \\
\text { seus usuários, quaisquer que sejam os modelos organizacionais; }\end{array}$ \\
\hline & IV - aplicar adequadamente a legislação inerente às funções contábeis; \\
\hline & $\begin{array}{l}\text { V - desenvolver, com motivação e através de permanente articulação, a liderança entre equipes } \\
\text { multidisciplinares para a captação de insumos necessários aos controles técnicos, à geração e } \\
\text { disseminação de informações contábeis, com reconhecido nível de precisão; }\end{array}$ \\
\hline & $\begin{array}{l}\text { VI - exercer suas responsabilidades com o expressivo domínio das funções contábeis, incluindo } \\
\text { noções de atividades atuariais e de quantificações de informações financeiras, patrimoniais e } \\
\text { governamentais, que viabilizem aos agentes econômicos e aos administradores de qualquer } \\
\text { segmento produtivo ou institucional o pleno cumprimento de seus encargos quanto ao } \\
\text { gerenciamento, aos controles e à prestação de contas de sua gestão perante à sociedade, gerando } \\
\text { também informações para a tomada de decisão, organização de atitudes e construção de valores } \\
\text { orientados para a cidadania; }\end{array}$ \\
\hline & $\begin{array}{l}\text { VII - desenvolver, analisar e implantar sistemas de informação contábil e de controle gerencial, } \\
\text { revelando capacidade crítico analítica para avaliar as implicações organizacionais com a } \\
\text { tecnologia da informação; }\end{array}$ \\
\hline & $\begin{array}{l}\text { VIII - exercer com ética e proficiência as atribuições e prerrogativas que lhe são prescritas } \\
\text { através da legislação específica, revelando domínios adequados aos diferentes modelos } \\
\text { organizacionais. }\end{array}$ \\
\hline
\end{tabular}

Fonte: Conselho Nacional de Educação (2004)

Madruga, Colossi e Biazus (2016) sustentam que o ensino superior em Ciências Contábeis é mais do que um status educacional de um contador, pois constitui-se em um valor social: formação de um profissional íntegro, honesto e com força de vontade para perseguir seus ideais pessoais e societários, estimulando o profissional a desenvolver espírito de pesquisa, consciência crítica, liderança, desenvoltura tecnológica, conscientização social, política econômica e ambiental e respeito às ordens institucionais, para que assim, seja capaz de distinguir um bom de um mau trabalho e tenha a capacidade de atingir seus ideais de forma ética, com elevada responsabilidade social.

Já para Marchalek et al. (2016), que analisaram as competências e habilidades do profissional contábil, verificou-se que características pessoais consideradas mais importantes para o desempenho do profissional contábil são a flexibilidade para mudanças, seguido da liderança e

Revista Eletrônica do Alto Vale do Itajaí - REAVI, v.10, nº 16, p. 001-017, ago. 2021. 
iniciativa do profissional, assim como a necessidade de trabalhar em equipe dentro da profissão.

Em relação ao desenvolvimento das competências do profissional contábil, Parsons, Davidowitz e Maughan (2020), relatam que avaliações dos pontos fortes e fracos continuam a impulsionar o aprendizado das competências, enquanto o material de "valor agregado" oferece pouca contribuição positiva para o desenvolvimento delas. Também expuseram que o feedback individual, trabalho em grupo e orientações contribuem para o desenvolvimento da competência profissional. Além disto, foi denotado que turmas grandes apresentam desafios práticos para implementar as ferramentas de aprendizagem eficazes.

Ao analisarem os conhecimentos, habilidades e atitudes inerentes ao profissional da contabilidade no atual mercado de trabalho brasileiro, Cosenza, Gomes e Devillart (2015) constatam que existe a necessidade de o contador conquistar maior credibilidade profissional e dispor de conhecimentos mais sólidos relativos ao controle de gestão. Também é necessário que possua conhecimentos em outras áreas, e que interajam no processo decisório das empresas, além de um pleno domínio da tecnologia da informação.

Na mesma linha de pensamento, Madruga, Colossi e Biazus (2016) observam que o perfil profissional esperado frente às transformações globais e suas implicações, influenciam as características profissionais e competências do contador, exigindo-lhe mudanças de atitude e comportamento frente às suas novas funções. O novo perfil requer uma atualização de sua concepção de gestão e uma visão de mundo mais ampla, capaz de perceber a realidade em que a organização se insere e a extensão de suas responsabilidades gerenciais. Além disto, suas posturas éticas baseadas em valores, precisam ter absoluta transparência para o efetivo exercício de sua liderança, no desempenho das funções gerenciais.

\subsection{ESTUDOS ANTERIORES SOBRE O TEMA}

A seguir, apresenta-se o Quadro 2, com estudos correlatos que abordaram a temática de competências do profissional contábil, especificando seus autores, objetivos e principais resultados.

\begin{tabular}{|c|c|c|}
\hline Autores & Objetivos & Principais Resultados \\
\hline $\begin{array}{l}\text { Alves et al. } \\
\text { (2016) }\end{array}$ & $\begin{array}{l}\text { Investigar as competências e } \\
\text { habilidades requeridas pelo } \\
\text { mercado de trabalho para o } \\
\text { profissional de contabilidade, no } \\
\text { estado de Minas Gerais, nos } \\
\text { níveis operacional, gerencial e } \\
\text { estratégico, na ótica dos } \\
\text { empregadores. }\end{array}$ & $\begin{array}{l}\text { Foi identificado um percentual relevante de demanda por } \\
\text { experiência prévia na área contábil. Dentre os grupos de } \\
\text { conhecimento mais exigidos aos profissionais da contabilidade, } \\
\text { destacam-se "experiência profissional", "tecnologia de } \\
\text { informação" e "áreas não específicas da contabilidade"; já o } \\
\text { grupo "normas contábeis internacionais e convergência das } \\
\text { normas brasileiras" foi aquele que obteve menor frequência de } \\
\text { exigência. }\end{array}$ \\
\hline $\begin{array}{l}\text { Galvão } \\
\text { (2016) }\end{array}$ & $\begin{array}{llr}\text { Verificar a percepção } & \text { de } \\
\text { estudantes do ensino médio, } & \text { mo } \\
\text { prestes a escolher o } & \text { curso } \\
\text { universitário, sobre } & \text { o } \\
\text { profissional contábil. } & \\
\end{array}$ & $\begin{array}{l}\text { Observou-se uma percepção positiva por parte dos respondentes } \\
\text { em relação ao profissional contábil. Quanto às características } \\
\text { pessoais do contador, os estudantes enxergam nesse profissional, } \\
\text { atributos como inteligência, criatividade e honestidade. }\end{array}$ \\
\hline $\begin{array}{l}\text { Madruga, } \\
\text { Colossi e } \\
\text { Biazus } \\
(2016)\end{array}$ & $\begin{array}{l}\text { Levantar alguns aspectos } \\
\text { conceituais da função gerencial, } \\
\text { com o objetivo de ressaltar a } \\
\text { pertinência de pesquisas } \\
\text { relacionadas à formação no } \\
\text { ensino superior do contador }\end{array}$ & $\begin{array}{l}\text { O novo perfil profissional de contador exigido pelo mercado, faz } \\
\text { com que seja necessário adotar algumas características e } \\
\text { tendências inovadoras essenciais, tais como espírito de iniciativa } \\
\text { e de decisão, capacidade de discernimento e senso crítico, para } \\
\text { julgar e escolher alternativas e conduta ética associada à } \\
\text { responsabilidade social e profissional. }\end{array}$ \\
\hline
\end{tabular}

Continua...

Revista Eletrônica do Alto Vale do Itajaí - REAVI, v.10, nº 16, p. 001-017, ago. 2021. 
...continuação.

\begin{tabular}{|c|c|c|}
\hline $\begin{array}{c}\text { Adam, } \\
\text { Cunha e } \\
\text { Boff } \\
(2018)\end{array}$ & $\begin{array}{l}\text { Analisar a produção científica } \\
\text { nacional no que concerne as } \\
\text { competências do contador na } \\
\text { perspectiva da universidade, } \\
\text { acadêmico e mercado de } \\
\text { trabalho. }\end{array}$ & $\begin{array}{l}\text { Entre as cinco competências mais citadas entre os artigos da } \\
\text { amostra, tem-se: conhecimento em contabilidade e finanças, } \\
\text { tecnologia da informação, ética e honestidade, idiomas e } \\
\text { raciocínio lógico, demonstrando a interdisciplinaridade } \\
\text { necessária para a formação do contador, visto que, somente uma } \\
\text { competência guarda relação direta com o eixo profissional do } \\
\text { contador. }\end{array}$ \\
\hline $\begin{array}{l}\text { Faotto e } \\
\text { Jung } \\
(2018)\end{array}$ & $\begin{array}{l}\text { Identificar a percepção } \text { de } \\
\text { acadêmicos de um curso de } \\
\text { Ciências Contábeis acerca das } \\
\text { habilidades, competências } \\
\text { tendências de mercado de } \\
\text { contadores, considerando os } \\
\text { cenários nacional } \\
\begin{array}{ll}\text { internacional. } & \end{array} \\
\end{array}$ & $\begin{array}{l}\text { A visão dos alunos está na mesma direção do mercado de } \\
\text { trabalho, ratificado pela questão } 8 \text {, nos itens "capacidade de } \\
\text { gestão" e "visão de negócio", apontado por eles como essenciais } \\
\text { para o desempenho da função de contador, deixando para traz a } \\
\text { antiga função do contador conhecida como "guarda livros", que } \\
\text { desempenhava um papel voltado para a contabilidade fiscal. }\end{array}$ \\
\hline $\begin{array}{l}\text { Silva e } \\
\text { Silva } \\
(2018)\end{array}$ & $\begin{array}{l}\text { Identificar quais } \text { são as } \\
\text { principais } \\
\text { competências do profissional } \\
\text { contábil, dentre outras } \\
\text { habilidades que fazem parte do } \\
\text { perfil mercadológico do } \\
\text { contador. }\end{array}$ & $\begin{array}{l}\text { As competências mais solicitadas aos profissionais contábeis } \\
\text { foram: em primeiro lugar na área de contabilidade e finanças } \\
\text { (conhecimento e experiência no setor de contábil e financeiro), } \\
\text { em segundo lugar na área legal (conhecimento e habilidade no } \\
\text { setor tributário e fiscal) e em seguida área de informática } \\
\text { (conhecimento, experiência e habilidade com sistemas e } \\
\text { informática em geral). }\end{array}$ \\
\hline $\begin{array}{l}\text { Wollinger, } \\
\text { Martins e } \\
\text { Marinho } \\
(2018)\end{array}$ & $\begin{array}{l}\text { Analisar a relação entre os } \\
\text { estilos de aprendizagem e as } \\
\text { competências } \quad \text { individuais } \\
\text { adquiridas, segundo a } \\
\text { perspectiva dos acadêmicos do } \\
\text { curso de graduação em Ciências } \\
\text { Contábeis. }\end{array}$ & $\begin{array}{l}\text { A maioria dos discentes do curso de Ciências Contábeis possui } \\
\text { como habilidades predominantes na aprendizagem, a } \\
\text { conceituação abstrata e a observação reflexiva, o que caracteriza } \\
\text { um raciocínio indutivo para estes alunos. Em relação às } \\
\text { competências, identificaram-se três fatores, por meio da análise } \\
\text { fatorial exploratória, que foram denominados competência ética } \\
\text { e de solução de problemas, competência sistêmica e analítica e } \\
\text { competência técnico-profissional. }\end{array}$ \\
\hline $\begin{array}{r}\text { Yanto } \\
(20\end{array}$ & 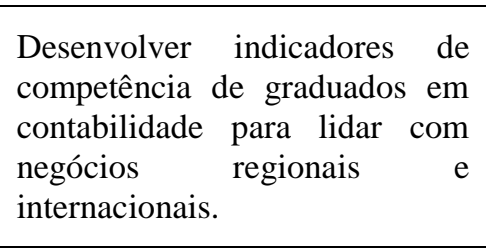 & $\begin{array}{l}\text { Foi identificado seis fatores de competência de graduados em } \\
\text { contabilidade para trabalhar em nível nacional e internacional, } \\
\text { sendo eles: competência intelectual e de tomada de decisão, } \\
\text { competência de comunicação e negociação, competência } \\
\text { operacional, competência em tecnologia, competência de } \\
\text { personalidade e competência gerencial. }\end{array}$ \\
\hline $\begin{array}{l}\mathrm{Si} \\
\text { al }\end{array}$ & $\begin{array}{l}\text { Aproximar competências } \\
\text { requeridas para a atuação } \\
\text { profissional com as exigidas no } \\
\text { exame de suficiência aplicadas } \\
\text { pelo Conselho Federal de } \\
\text { Contabilidade (CFC). }\end{array}$ & $\begin{array}{l}\text { Constatou-se que as provas contemplam nos eixos técnico- } \\
\text { profissional, relacional e organizacional um perfil de contador } \\
\text { com "competência técnica", "credibilidade e confiança", } \\
\text { "domínio da "comunicação oral e escrita", "visão sistêmica", } \\
\text { capacidade para a "aplicação de conhecimento", "resolução de } \\
\text { problemas", "planejamento", que seja "flexível" e saiba } \\
\text { "administrar conflitos". }\end{array}$ \\
\hline $\begin{array}{c}\text { Parsons, } \\
\text { Davidowitz } \\
\text { e Maughan } \\
(2020)\end{array}$ & $\begin{array}{l}\text { Contribuir para a literatura sobre } \\
\text { educação contábil, identificando } \\
\text { temas no design do programa } \\
\text { que informaram r o } \\
\text { desenvolvimento efetivo da } \\
\text { competência profissional no } \\
\text { contexto do programa } \\
\text { preparatório }\end{array}$ & $\begin{array}{l}\text { A avaliação continuou a impulsionar o aprendizado, enquanto o } \\
\text { material de "agregação de valor" fez pouca contribuição positiva. } \\
\text { O desenvolvimento de habilidades mostrou-se mais eficaz } \\
\text { quando explícito. O feedback individual, o trabalho em grupo e a } \\
\text { orientação contribuíram positivamente para o desenvolvimento } \\
\text { da competência profissional, enquanto a contribuição das } \\
\text { palestras foi menos clara. }\end{array}$ \\
\hline
\end{tabular}

Fonte: Elaborado pelos Autores (2021)

Percebeu-se que os resultados referentes às competências dos profissionais contábeis estão voltados, em sua maioria, ao âmbito técnico. Em outras palavras, são mais requisitadas

Revista Eletrônica do Alto Vale do Itajaí - REAVI, v.10, nº 16, p. 001-017, ago. 2021. 
competências que envolvam escriturações, apurações, conhecimentos em legislação e contabilidade tributária, conhecimentos e habilidades em tecnologia da informação e conhecimentos relativos a questões trabalhistas.

O trabalho de Adam, Cunha e Boff (2018) evidencia que entre as cinco competências mais citadas em suas amostras, apenas uma destas competências, sendo ela, conhecimento em contabilidade e finanças, possui relação direta no que diz respeito ao eixo profissional do contador. Desta forma, denota-se a necessidade de exercer a união de conhecimentos e competências de mais disciplinas para a formação do profissional contábil.

\section{PROCEDIMENTOS METODOLÓGICOS}

O estudo realizado classifica-se quanto à abordagem, como quantitativo, descritivo, decorrente dos objetivos e, em relação aos procedimentos, trata-se de uma pesquisa de levantamento. Como instrumento de coleta de dados, aplicou-se um questionário, baseado nas pesquisas de Faotto e Jung (2018), Wollinger, Martins e Marinho (2018), Moura e Filho (2019) e Silva et al. (2020), contendo 11 (onze) questões fechadas, validado por professores da área e aplicado por meio eletrônico no período entre 20 de agosto e 20 de setembro de 2020. Cabe destacar que o instrumento foi disponibilizado por meio da plataforma Google Formulários ${ }^{\text {e foi }}$ encaminhado à população deste estudo via e-mail, enviado pela coordenação dos cursos.

A população deste artigo foi de 335 alunos matriculados em 2020/2 nos cursos de Ciências Contábeis de uma universidade comunitária de Santa Catarina (256 no campus A e 79 no campus B), resultando em uma amostra de 111 respondentes, que representa $33,13 \%$ da população. Os dados coletados foram tabulados por meio do Google Formulários ${ }^{\circledR}$ e utilizou-se como técnica de análise de dados, a estatística descritiva, segundo a distribuição de frequência relativa.

\section{ANÁLISE DOS RESULTADOS}

Neste capítulo, são abordados os resultados da pesquisa, separados em duas seções. A primeira, trata do perfil dos respondentes e, a segunda, dos resultados obtidos em relação às competências do profissional contábil. Desta forma, iniciando a análise da primeira seção, é possível identificar o gênero dos participantes desta pesquisa (Tabela 1).

Tabela 1 - Gênero

\begin{tabular}{c|c}
\hline Gênero & Frequência Relativa \\
\hline Feminino & $62,20 \%$ \\
\hline Masculino & $37,80 \%$ \\
\hline Total & $\mathbf{1 0 0 , 0 0 \%}$ \\
\hline
\end{tabular}

Fonte: Dados da Pesquisa (2021)

Observa-se que a maior parte dos respondentes foram do gênero feminino, com a frequência de 62,20\%, enquanto o gênero masculino representou somente $37,80 \%$ dos participantes do estudo, não representando um equilíbrio entre o gênero dos alunos. Na Tabela 2, pode-se verificar a faixa etária e período em que os respondentes estão matriculados.

Tabela 2 - Faixa Etária e Período

\begin{tabular}{c|c|c|c}
\hline Idade & Frequência Relativa & Período & Frequência Relativa \\
\hline Até 20 Anos & $32,43 \%$ & $1^{\circ}$ Período & $0,00 \%$ \\
\hline de 21 a 25 Anos & $43,25 \%$ & $2^{\circ}$ Período & $13,50 \%$ \\
\hline de 26 a 30 Anos & $18,02 \%$ & $3^{\circ}$ Período & $3,70 \%$ \\
\hline de 31 A 35 Anos & $0,00 \%$ & $4^{\circ}$ Período & $23,40 \%$ \\
\hline
\end{tabular}

Revista Eletrônica do Alto Vale do Itajaí - REAVI, v.10, nº 16, p. 001-017, ago. 2021. 


\begin{tabular}{c|c|c|c}
\multirow{2}{*}{ de 36 a 40 Anos } & $4,50 \%$ & $5^{\circ}$ Período & ..continuação. \\
\cline { 3 - 3 } & $1,80 \%$ & $6^{\circ}$ Período & $12,60 \%$ \\
\hline de 41 a 45 Anos & $0,00 \%$ & $7^{\circ}$ Período & $9,90 \%$ \\
\hline de 46 a 50 Anos & $0,00 \%$ & $8^{\circ}$ Período & $32,40 \%$ \\
\hline 51 Anos ou mais & $\mathbf{1 0 0 , 0 0 \%}$ & Total & $\mathbf{1 0 0 , 0 0 \%}$ \\
\hline Total & &
\end{tabular}

Fonte: Dados da Pesquisa (2021)

Verifica-se que a maior parte dos respondentes da pesquisa estão concentrados na faixa etária de até 25 anos, representando 75,68\%, sendo 43,25\% na faixa etária de 21 a 25 anos. Desta forma, nota-se que os participantes deste artigo podem ser considerados jovens, resultado razoavelmente esperado, considerando a população de universitários. Em relação ao período em que os respondentes estão matriculados, observa-se que a maior frequência observada foi no oitavo período, com $32,40 \%$. Também verifica-se que a maioria dos alunos que responderam à pesquisa, estão matriculados na parte final do curso $\left(5^{\circ}\right.$ a $8^{\circ}$ período), com $59,40 \%$.

Cabe destacar que no primeiro período dos cursos, quando da elaboração deste estudo, haviam somente 5 acadêmicos matriculados e, neste caso, nenhum destes respondeu a pesquisa. No demonstrativo abaixo, verifica-se o percentual correspondente ao campus de origem dos respondentes desta pesquisa (Tabela 3 ).

Tabela 3 - Campus

\begin{tabular}{c|c} 
Curso & Frequência Relativa \\
\hline Ciências Contábeis - Campus A & $69,40 \%$ \\
\hline Ciências Contábeis - Campus B & $30,60 \%$ \\
\hline Total & $\mathbf{1 0 0 , 0 0 \%}$ \\
\hline
\end{tabular}

Fonte: Dados da Pesquisa (2021)

Em relação ao campus dos graduandos de Ciências Contábeis, observa-se que a maior parte dos respondentes são do campus A, no qual representam $69,40 \%$, enquanto o campus B representa $30,60 \%$. Este resultado segue a distribuição da população, uma vez que o campus A possui um número maior de alunos matriculados. A seguir, apresentam-se os dados referentes ao trabalho ou estágio dos graduandos (Tabela 4).

Tabela 4 - Área de Atuação

\begin{tabular}{c|c}
\hline Trabalho / Estágio & Frequência Relativa \\
\hline Não trabalho/faço estágio atualmente & $11,71 \%$ \\
\hline Não trabalho/faço estágio na área contábil & $6,31 \%$ \\
\hline Fiscal & $23,43 \%$ \\
\hline Contábil & $31,54 \%$ \\
\hline Planejamento Tributário & $0,90 \%$ \\
\hline Pessoal & $7,21 \%$ \\
\hline Societário & $0,00 \%$ \\
\hline Outros & $18,90 \%$ \\
\hline Total & $\mathbf{1 0 0 , 0 0 \%}$ \\
\hline
\end{tabular}

Fonte: Dados da Pesquisa (2021)

Em relação ao âmbito profissional, pode-se observar que a maior parte dos respondentes trabalham ou fazem estágio na área fiscal ou área contábil, representando 54,97\%, enquanto $11,71 \%$ não trabalham ou fazem estágio atualmente. Observa-se também que nenhum aluno atua na área Societária. A seguir, inicia-se a análise da segunda seção, onde se aborda as competências do profissional contábil na percepção dos alunos de graduação em Ciências Contábeis. Sendo assim, na Tabela 5, apresenta-se a principal função do contador.

Revista Eletrônica do Alto Vale do Itajaí - REAVI, v.10, nº 16, p. 001-017, ago. 2021. 
Tabela 5 - Principal Função do Contador

\begin{tabular}{c|c}
\hline Principal Função do contador & Frequência Relativa \\
\hline Controlar patrimônio & $4,50 \%$ \\
\hline Controlar a parte financeira & $7,20 \%$ \\
\hline Analisar/Assessorar gestores na tomada de decisão & $68,50 \%$ \\
\hline Obrigações acessórias/ Fisco & $13,50 \%$ \\
\hline Planejamento Tributário & $6,30 \%$ \\
\hline Total & $\mathbf{1 0 0 , 0 0 \%}$ \\
\hline
\end{tabular}

Fonte: Dados da Pesquisa (2021)

De acordo com as respostas obtidas, foi possível verificar que a maioria dos respondentes $(68,50 \%)$, acredita que a principal função do contador é a de analisar/assessorar gestores na tomada de decisão. Este resultado pode ser uma consequência do fato de que a maioria dos respondentes não pertencerem a períodos iniciais, pois nestes períodos, a principal função do contador ainda pode não estar muito clara para estes acadêmicos. O resultado obtido vai ao encontro da pesquisa de Faotto e Jung (2018), quando 62,07\% dos concluintes do curso de Ciências Contábeis acreditam que a principal função do contador é a de assessorar gestores na tomada de decisão. No demonstrativo abaixo, apresenta-se a importância das competências e habilidades do profissional contábil, segundo os respondentes deste questionário (Tabela 6).

Tabela 6 - Competências e Habilidades

\begin{tabular}{|c|c|c|c|c|c|c|}
\hline & 乙气 & 音 & 音 & 㤩 & 되 & \\
\hline Liderança & $2,70 \%$ & $0,90 \%$ & $18,02 \%$ & $36,94 \%$ & $41,44 \%$ & $100,00 \%$ \\
\hline Proatividade & $1,80 \%$ & $0,90 \%$ & $9,91 \%$ & $29,73 \%$ & $57,66 \%$ & $100,00 \%$ \\
\hline Capacidade de Gestão & $2,70 \%$ & $1,80 \%$ & $10,81 \%$ & $29,73 \%$ & $54,96 \%$ & $100,00 \%$ \\
\hline Relacionamento Interpessoal & $2,70 \%$ & $0,00 \%$ & $10,81 \%$ & $26,13 \%$ & $60,36 \%$ & $100,00 \%$ \\
\hline Visão de Negócio & $1,80 \%$ & $3,60 \%$ & $10,81 \%$ & $27,03 \%$ & $56,76 \%$ & $100,00 \%$ \\
\hline Criatividade e Inovação & $0,00 \%$ & $4,50 \%$ & $20,72 \%$ & $33,33 \%$ & $41,45 \%$ & $100,00 \%$ \\
\hline Práticas Contábeis & $2,70 \%$ & $0,90 \%$ & $8,12 \%$ & $24,32 \%$ & $63,96 \%$ & $100,00 \%$ \\
\hline Legislação & $2,70 \%$ & $1,80 \%$ & $14,42 \%$ & $20,72 \%$ & $60,36 \%$ & $100,00 \%$ \\
\hline Elaborar e Interpretar Cenários & $2,70 \%$ & $1,80 \%$ & $9,91 \%$ & $28,83 \%$ & $56,76 \%$ & $100,00 \%$ \\
\hline Raciocínio Lógico, Crítico e Analítico & $2,70 \%$ & $0,00 \%$ & $9,01 \%$ & $27,03 \%$ & $61,26 \%$ & $100,00 \%$ \\
\hline
\end{tabular}

Fonte: Dados da Pesquisa (2021)

Segundo os dados coletados, pode-se afirmar que a maioria dos respondentes consideram a presença das competências e habilidades relacionadas acima muito importantes no perfil do profissional contábil. Este achado vai ao encontro da pesquisa efetuada por Faotto e Jung (2018), no qual obtiveram resultados semelhantes, com exceção apenas das competências relacionamento interpessoal e criatividade, no qual a presente pesquisa obteve resultados superiores no fator da importância dos citados anteriormente.

Também verifica-se que as competências com maiores percentuais de muita ou extrema importância são a proatividade com $87,39 \%$, o relacionamento interpessoal, representando $86,49 \%$, as práticas contábeis, com $88,28 \%$, elaborar e interpretar cenários somando $85,59 \%$ e o raciocínio lógico, crítico e analítico com $88,29 \%$. Isto está de acordo com alguns atributos citados por Silveira et al. (2019), no qual os bacharéis em Ciências Contábeis deverão ser capazes de elaborar pareceres e relatórios contábeis que possam contribuir para uma eficiente e eficaz interpretação por parte dos usuários, quaisquer que sejam os modelos organizacionais, aplicar

Revista Eletrônica do Alto Vale do Itajaí - REAVI, v.10, nº 16, p. 001-017, ago. 2021. 
adequadamente a legislação inerente às funções contábeis, promover com motivação e permanente articulação, a liderança entre equipes multidisciplinares para captar insumos necessários aos controles técnicos, a geração e disseminação de informações contábeis, com reconhecido nível de precisão e exatidão. A seguir, tem-se a opinião dos respondentes acerca da importância do profissional contábil no mercado (Tabela 7).

Tabela 7 - Importância do profissional contábil

\begin{tabular}{c|c}
\hline Importância do profissional contábil no mercado & Frequência Relativa \\
\hline Nenhuma Importância & $0,00 \%$ \\
\hline Pouca Importância & $0,00 \%$ \\
\hline Média Importância & $2,70 \%$ \\
\hline Muita Importância & $25,20 \%$ \\
\hline Extrema Importância & $72,10 \%$ \\
\hline Total & $\mathbf{1 0 0 , 0 0 \%}$ \\
\hline
\end{tabular}

Fonte: Dados da Pesquisa (2021)

Para a maior parte dos respondentes $(97,30 \%)$, verifica-se que o profissional contábil possui muita ou extrema importância no mercado, sendo os serviços contábeis muito relevantes para a sociedade, justamente por seus conhecimentos, habilidades e competências necessárias serem relevantes para a gestão de uma organização, conforme aponta Silva et al. (2020). Este resultado também vai ao encontro das considerações apresentadas por Madruga, Colossi e Biazus (2016), que indicam que o profissional contábil passou a ter importância no processo decisório, tendo em vista que possui uma visão mais ampla do cenário empresarial, e seu trabalho deixa de ser apenas uma ferramenta operacional de transcrição de valores e resultados contábeis, criando, assim, a necessidade de também assumir questões gerenciais internas. No próximo demonstrativo, apresenta-se a opinião dos respondentes sobre as características pessoais do contador (Tabela 8).

Tabela 8 - Características Pessoais do Contador

Características pessoais do Contador

\begin{tabular}{|c|c|c|c|c|c|c|}
\hline Características pessoais do Contador & 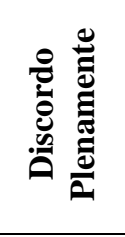 & 莺 & 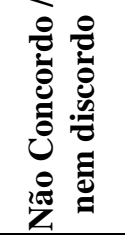 & 莺 & 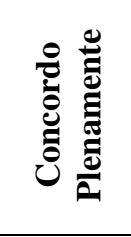 & \\
\hline Gosta de rotinas & $6,31 \%$ & $11,71 \%$ & $19,82 \%$ & $38,74 \%$ & $23,42 \%$ & $100,00 \%$ \\
\hline Gosta de números & $2,70 \%$ & $3,60 \%$ & $12,61 \%$ & $45,05 \%$ & $36,04 \%$ & $100,00 \%$ \\
\hline É preciso e focado & $0,00 \%$ & $1,80 \%$ & $14,42 \%$ & $20,72 \%$ & $63,06 \%$ & $100,00 \%$ \\
\hline É organizado & $0,90 \%$ & $2,70 \%$ & $6,31 \%$ & $26,13 \%$ & $63,96 \%$ & $100,00 \%$ \\
\hline Gosta de burocracia & $18,92 \%$ & $18,02 \%$ & $27,03 \%$ & $24,32 \%$ & $11,71 \%$ & $100,00 \%$ \\
\hline É honesto & $0,00 \%$ & $0,00 \%$ & $13,51 \%$ & $18,92 \%$ & $67,57 \%$ & $100,00 \%$ \\
\hline É inteligente & $0,00 \%$ & $0,00 \%$ & $14,41 \%$ & $25,23 \%$ & $60,36 \%$ & $100,00 \%$ \\
\hline É criativo & $0,90 \%$ & $5,40 \%$ & $27,93 \%$ & $35,14 \%$ & $30,63 \%$ & $100,00 \%$ \\
\hline
\end{tabular}

Fonte: Dados da Pesquisa (2021)

Segundos os dados coletados, pode-se verificar uma alta concordância (parcial ou plenamente), com as características de maior destaque: a honestidade $(67,57 \%)$, organização (63,96\%), foco e precisão $(63,06 \%)$ e inteligência $(60,36 \%)$. Destaca-se que 36,94\% dos respondentes discordam (parcial ou plenamente) da afirmativa de o profissional contábil gostar de burocracia. Os resultados obtidos corroboram com a pesquisa de Galvão (2016), onde também foram evidenciadas fortes concordâncias em relação à honestidade, inteligência, foco e organização. A seguir, é apresentado o nível de importância de cada uma das competências listadas na Tabela 9, conforme a percepção dos respondentes.

Revista Eletrônica do Alto Vale do Itajaí - REAVI, v.10, nº 16, p. 001-017, ago. 2021. 
Tabela 9 - Nível de Importância das Competências

\section{Competências do profissional contábil}

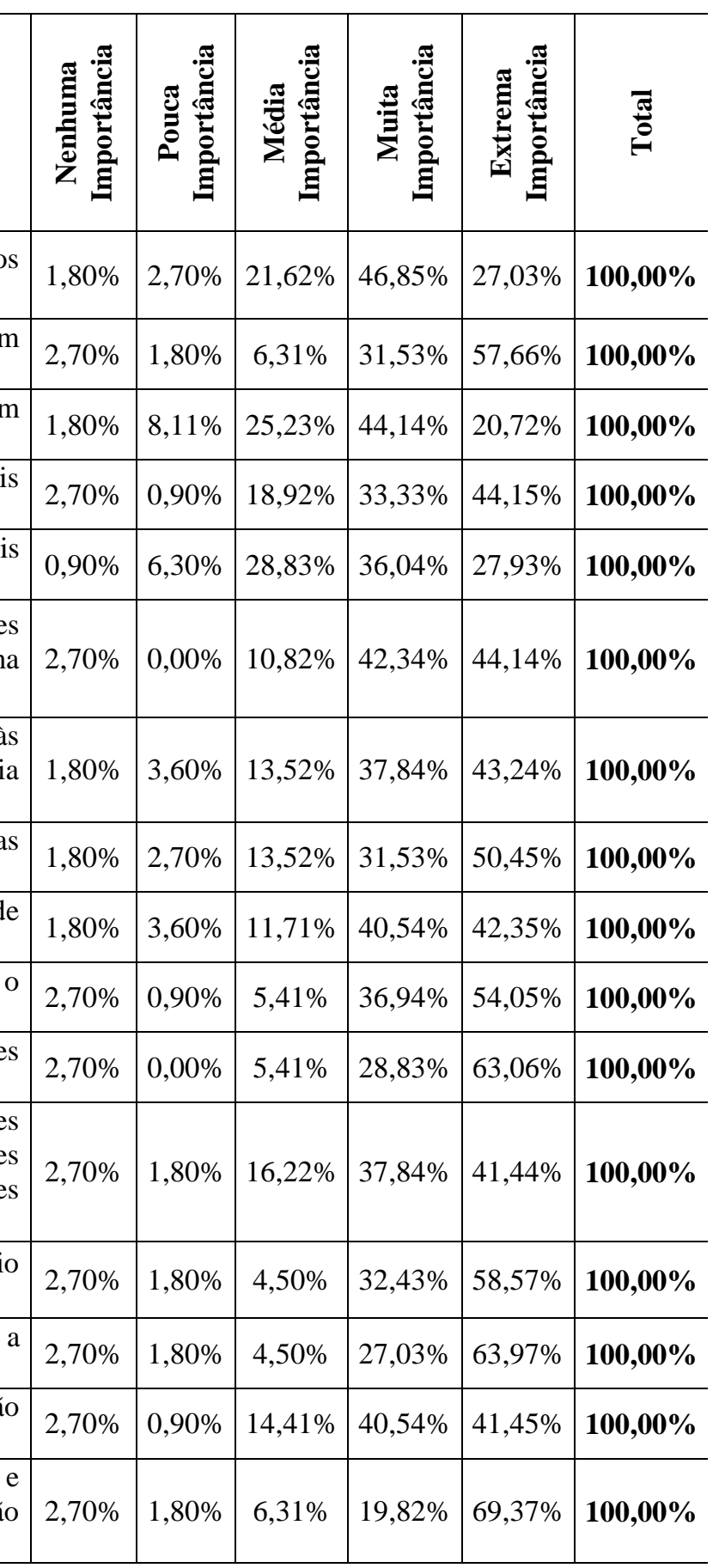

Compreender questões científicas, técnicas, sociais nos

diferentes modelos de organização.

Compreender questões econômicas e financeiras em âmbito nacional.

Compreender questões econômicas e financeiras em âmbito internacional.

Ter o domínio das responsabilidades funcionais envolvendo apurações e auditorias.

Ter o domínio das responsabilidades funcionais envolvendo perícias e arbitragens.

Possuir noções de quantificações de informações financeiras, patrimoniais e governamentais, com a plena utilização de inovações tecnológicas.

Ter capacidade crítico analítica de avaliação, quanto às implicações organizacionais com o advento da tecnologia da informação.

Utilizar adequadamente a terminologia e a linguagem das

Ciências Contábeis.

Demonstrar visão sistêmica e interdisciplinar da atividade contábil.

Elaborar pareceres e relatórios que contribuam para o desempenho eficiente e eficaz de seus usuários.

Aplicar adequadamente as legislações relativas às funções contábeis.

Desenvolver, com motivação, a liderança entre equipes multidisciplinares para captação de informações necessárias para a disseminação das informações contábeis.

Exercer suas responsabilidades com o expressivo domínio das funções contábeis.

Gerar informações úteis para a tomada de decisão e para a prestação de contas perante a sociedade.

Desenvolver, analisar e implantar sistemas de informação contábil e de controle gerencial.

Exercer com ética e proficiência as atribuições e prerrogativas que lhe são prescritas por meio da legislação específica.

Fonte: Dados da Pesquisa (2021)

Conforme a Tabela 9, pode-se afirmar que a maioria dos respondentes considera todas as competências do profissional contábil acima citadas, de muita ou extrema importância. Foi possível verificar que as competências de maior importância para os respondentes, são: compreender questões econômicas e financeiras em âmbito nacional $(89,19 \%)$, elaborar pareceres e relatórios que contribuam para o desempenho eficiente e eficaz de seus usuários $(90,99 \%)$, aplicar adequadamente as legislações relativas às funções contábeis $(91,89 \%)$, exercer suas responsabilidades com o expressivo domínio das funções contábeis $(91,00 \%)$, gerar informações úteis para a tomada de decisão e para a prestação de contas perante a sociedade $(91,00 \%)$ e exercer

Revista Eletrônica do Alto Vale do Itajaí - REAVI, v.10, nº 16, p. 001-017, ago. 2021. 
com ética e proficiência as atribuições e prerrogativas que lhe são prescritas por meio da legislação específica $(89,19 \%)$.

De acordo com os resultados obtidos, é possível notar que os respondentes acreditam que o contador precisa ter pleno conhecimento acerca de questões que envolvem economia no âmbito nacional, mas não acham que o profissional precisa ter pleno conhecimento sobre questões que envolvam a economia internacional, nem que ele precise estar tão atento as atribuições que envolvam perícias e arbitragens. É possível notar também que o contador precisa elaborar pareceres que contribuam com os gestores na tomada decisão, corroborando assim, com os resultados encontrados na Tabela 5 .

Nota-se também que o profissional precisa conhecer as legislações vigentes e exercer a profissão com ética. Os resultados também apontam que as competências de maior importância, na percepção dos respondentes, são aquelas que se observam com maior frequência durante o curso ou em suas experiências profissionais, explicando assim, o motivo de as competências relacionadas ao âmbito internacional serem as consideradas de menor importância, uma vez que são as menos observadas e vivenciadas nas experiências profissionais dos acadêmicos. $\mathrm{O}$ mesmo vale para a baixa importância dada às perícias e arbitragens, já que são áreas vivenciadas, em sua maioria, por profissionais já formados e que possuem vasta experiência na área. Sendo assim, o estudo corrobora com a pesquisa de Wollinger, Martins e Marinho (2018), que aponta a importância das competências relacionadas à ética e resolução de problemas, competência sistêmica e analítica e competência técnico-profissional. A seguir, são apresentadas as competências do contador mais requisitadas, conforme a percepção dos alunos (Tabela 10).

Tabela 10 - Competências do Contador requisitadas

\begin{tabular}{l|c}
\multicolumn{1}{c|}{ Competências do contador mais requisitadas } & Frequência Relativa \\
\hline Análise e resolução de problema ou situação & $16,22 \%$ \\
\hline Ter uma boa comunicação & $7,21 \%$ \\
\hline Possuir visão estratégica & $5,41 \%$ \\
\hline Conhecer e utilizar a informática como ferramenta & $1,80 \%$ \\
\hline Transmitir integridade e confiança & $4,50 \%$ \\
\hline Buscar boas opções para atender interesses dos envolvidos e da empresa (Negociação) & $2,70 \%$ \\
\hline Possuir um bom atendimento, saber entender e dialogar & $2,70 \%$ \\
\hline Gestão da Informação & $3,60 \%$ \\
\hline $\begin{array}{l}\text { Dominar e interpretar os conceitos relacionados à área de contabilidade e finanças } \\
\text { empresariais (Contabilidade e Finanças) }\end{array}$ & $30,64 \%$ \\
\hline Estuda e aplica conceitos de planejamento e acompanhamentos estratégico, operacional & $19,82 \%$ \\
\hline financeiro (Planejamento) & $0,00 \%$ \\
\hline Autocontrole & $0,00 \%$ \\
\hline Ser um bom empreendedor & $1,80 \%$ \\
\hline Possuir ferramentas de controle sobre seus serviços & $0,90 \%$ \\
\hline Saber trabalhar em equipe & $0,90 \%$ \\
\hline Relacionamento Externo & $0,00 \%$ \\
\hline Técnicas de Gestão & $1,80 \%$ \\
\hline Total & $\mathbf{1 0 0 , 0 0 \%}$ \\
\hline
\end{tabular}

Fonte: Dados da Pesquisa (2021)

Pode-se verificar que na visão dos respondentes, a competência profissional mais requisitada do contador é dominar e interpretar os conceitos relacionados à área de contabilidade e finanças empresariais (contabilidade e finanças), representando 30,64\%. Em seguida, a competência estuda e aplica conceitos de planejamento e acompanhamentos estratégico, operacional e financeiro (planejamento) e análise e resolução de problema ou situação, representam $19,82 \%$ e 16,22\%, respectivamente. Isto pode indicar uma necessidade mais elevada

Revista Eletrônica do Alto Vale do Itajaí - REAVI, v.10, nº 16, p. 001-017, ago. 2021. 
por parte do mercado de trabalho, de profissionais competentes em contabilidade, finanças, planejamento e que saibam analisar e solucionar problemas ou situações. Outro ponto que podese verificar é a competência "Técnicas de Gestão", onde apenas 1,80\% dos respondentes acreditam ser uma das competências requisitas, e isso vai de encontro com as respostas obtidas na Tabela 5, onde a maioria dos respondentes acredita que a função do contador é de analisar/assessorar os gestores na tomada de decisão. Pode-se observar também, que as competências de autocontrole, ser um bom empreendedor e relacionamento externo não são vistas como competências requisitadas pelos respondentes. Posto isto, o estudo vai ao encontro da pesquisa de Silveira et al. (2019), que evidencia as competências de análise e resolução de problemas, estudo e aplicação dos conceitos e conhecimentos, como as mais requeridas pelo mercado de trabalho.

\section{CONSIDERAÇÕES FINAIS}

A presente pesquisa teve como objetivo analisar a percepção de alunos de graduação em Ciências Contábeis acerca das competências do profissional contábil. No que tange à principal função do profissional contábil, a grande maioria dos respondentes compreende que é a de analisar/assessorar os gestores na tomada de decisão, o que prova que o curso de Ciências Contábeis cumpre com o papel de deixar isto claro para os estudantes.

Referente às competências e habilidades do profissional contábil, verificou-se que as práticas contábeis, legislação e o raciocínio lógico, crítico e analítico possuem maior importância. Isto se deve ao fato que o profissional contábil é responsável por auxiliar as empresas nos enquadramentos legais e fiscais. Em relação à importância do profissional contábil no mercado, a maioria dos respondentes acredita que o contador possui uma importância muito relevante no mercado atual, auxiliando os empresários na tomada de decisão, aplicando seus conhecimentos e habilidades para fornecer informações confiáveis e tempestivas.

Portanto, verificou-se que o contador possui importância na gestão empresarial, pois auxilia por meio de informações, planejamentos e demonstrativos, a tomada de decisão. Sendo assim, o profissional amplia sua rede de atuação, deixando de ser apenas um gerador de dados, para se tornar uma peça importante no qual apresenta as melhores alternativas para o direcionamento das decisões empresariais.

Em relação às características e competências dos profissionais contábeis, a pesquisa indica que o contador é um profissional organizado, preciso e focado. São características necessárias para o desenvolvimento das competências mais exigidas no mercado, sendo estas competências a análise e resoluções de problemas, domínio da área de contabilidade e finanças empresariais, estudar e aplicar conceitos de planejamento, bem como acompanhamentos estratégicos, operacionais e financeiros. Isto aponta que o profissional contábil precisa manter a melhoria contínua de seus conhecimentos para que possa realizar um planejamento em múltiplas áreas e possa agir em tempo hábil para solucionar problemas na organização.

Também foi possível verificar que as competências relacionadas à ética e resolução de problemas, competência sistêmica e analítica e competência técnico-profissional, são as que o profissional precisa dominar, de acordo com os respondentes. Isto significa que o contador necessita dispor de diversas habilidades para atuar na profissão, habilidades estas que irão possibilitar que elabore relatórios precisos que irão revelar de maneira clara e objetiva a posição patrimonial e financeira da entidade, auxiliando os gestores na tomada de decisão.

Diante destes resultados, concluiu-se que a percepção dos graduandos acerca das competências do profissional contábil, vai em sua grande maioria, ao encontro do que estabelece a Resolução CNE/CES 10, de 16 de dezembro de 2004, que instituiu as diretrizes curriculares nacionais para o curso de graduação em Ciências Contábeis. Desta forma, pode-se concluir que o curso de Ciências Contábeis vem preparando seus discentes de maneira adequada, demonstrando

Revista Eletrônica do Alto Vale do Itajaí - REAVI, v.10, nº 16, p. 001-017, ago. 2021. 
quais habilidades e competências devem desenvolver e aprimorar, com o objetivo de se tornarem contadores aptos a atuar no mercado de trabalho. Foi possível concluir também que os alunos vêm se adaptando ao novo perfil profissional do contador, que exige do profissional uma visão mais ampla da empresa, com maior foco em suas responsabilidades gerenciais, fazendo com que o profissional seja cada vez mais valorizado no mercado de trabalho.

Assim sendo, evidencia-se que esta pesquisa pode contribuir com os discentes e docentes do curso de Ciências Contábeis, no sentido de proporcionar uma visão mais aprofundada acerca das principais e mais recorrentes competências do profissional contábil, possibilitando que seja ofertado pelos docentes um ensino mais efetivo na formação profissional de seus alunos e também servir como facilitador para os discentes definirem com maior segurança sua área de especialização, com base nos requisitos do mercado de trabalho.

O estudo apresenta como limitação, a sua amostra, cuja representatividade é de somente $33,13 \%$ da população pesquisada. Isto se deve ao fato de o questionário não ter sido aplicado presencialmente por conta das ações preventivas contra a propagação do vírus COVID-19 em 2020, uma vez que os graduandos tendem a ser mais participativos quando o questionário é aplicado de forma presencial. Outro fator que limitou a amostra, foi o fato de o questionário ser enviado por $e$-mail aos estudantes do curso, visto que muitos alunos não acessam o $e$-mail com frequência ou até mesmo, recebem muitos e-mails no dia, o que pode ter dificultado a visualização da mensagem contendo o questionário.

Sugere-se para trabalhos futuros, que esta pesquisa seja replicada em outras instituições do estado de Santa Catarina e até mesmo em outros estados, para que seja possível a comparação de resultados. Também se recomenda efetuar esta mesma pesquisa, com os profissionais formados em Ciências Contábeis e que estejam atuando na profissão, para verificar se as competências e habilidades respondidas neste estudo, de fato são requisitadas. Por fim, propõe-se um estudo qualitativo, com o intuito de compreender como as competências interferem na vida profissional do contador.

\section{REFERÊNCIAS}

ADAM, C.; CUNHA, P. R.; BOFF, M. L. Competências do contador na perspectiva da tríade universidade, acadêmico e mercado de trabalho. Revista de Contabilidade da UFBA, v. 12, n. 3, p. 221-245, 2018.

ALVES, P. M.; SILVA, R. M.; SANTOS, S. S.; ROCHA NETO, I. V.; PINHEIRO, D. R. O.; COSTA, J. E. S.; LEAL, E. A. Habilidades e competências requeridas pelo mercado de trabalho para o profissional de contabilidade em Minas Gerais. Revista Eletrônica do Alto Vale do Itajaí, v. 5, n. 8, p. 14-28, 2016.

ARAUJO, M. R.; PUREZA, M. L. B. O. H.; SILVA, C. A. T. Lei n 6.404/76: Uma análise dos principais avanços proporcionados à contabilidade no Brasil. Revista de Gestão e

Contabilidade da UFPI, v. 2, n. 2, p. 17-32, 2016.

CONSELHO NACIONAL DE EDUCAÇÃO. Resolução CNE/CES 10, de 16 de dezembro de 2004. Institui as diretrizes curriculares nacionais para o curso de graduação em Ciências Contábeis, bacharelado, e dá outras providências. Disponível em: http://portal.mec.gov.br/cne/arquivos/pdf/rces10_04.pdf. Acesso em: 13 nov. 2020.

Revista Eletrônica do Alto Vale do Itajaí - REAVI, v.10, nº 16, p. 001-017, ago. 2021. 
COSENZA, J. P.; GOMES, R. C.; DEVILLART, D. G. C. Habilidades e competências inerentes ao profissional da contabilidade no atual mercado de trabalho brasileiro. Revista Brasileira de Contabilidade, v. 214, n. 1, p. 32-57, 2015.

FAOTTO, C. L. F.; JUNG, C. F. Perfil e tendências profissionais no âmbito nacional e internacional: Um estudo acerca da percepção de acadêmicos de um curso de Ciências Contábeis do Vale do Paranhana - RS. Revista Eletrônica do Curso de Ciências Contábeis, v. 7, n. 1, p. 171-199, 2018.

GALVÃO, N. Percepção dos estudantes do ensino médio acerca do profissional contábil. Revista Evidenciação Contábil \& Finanças, v. 4, n. 2, p. 40-53, 2016.

GOMES, J. K. O.; WALTER, S. A.; SOUTES, D. O. A institucionalização da imagem da profissão contábil: Percepção de gestores de micro e pequenas empresas. Revista Contemporânea de Contabilidade, v. 16, n. 40, p. 126-147, 2019.

MADRUGA, S. R.; COLOSSI, N.; BIAZUS, C. A. Funções e competências gerenciais do contador. Revista de Administração da Universidade Federal de Santa Maria, v. 9, n. 2, p. 182-191, 2016.

MARCHALEK, A. L.; BERTOLlO, D. L.; CASTILHOS, N. C.; CAMARGO, M. E. Perfil do contador na atualidade: Um estudo exploratório na região metropolitana da Serra Gaúcha. In: MOSTRA DE INICIAÇÃO CIENTÍFICA, PÓS-GRADUAÇÃO, PESQUISA E EXTENSÃO, 16, 2016, Caxias do Sul/RS. Anais [...]. Caxias do Sul: UCS, 2016.

MOURA, M. M. S. G.; LIMA FILHO, R. N. A percepção dos alunos do curso de Ciências Contábeis quanto a sua formação acadêmica em relação ao mercado de trabalho. Brazilian Journal of Development, v. 5, n. 1, p. 386-415, 2019.

OLIVEIRA, B.; BENETTI, J. E. Importância do profissional da contabilidade na gestão de micro e pequenas empresas localizadas em Chapecó/SC. Revista Científica Tecnológica, v. 5, n. 2, p. 178-196, 2016.

OLIVEIRA, M. Q.; PIZANNI, M. A.; FARIA, J. A. A interdisciplinaridade na formação do contador e sua contribuição para o desenvolvimento de competências no âmbito organizacional. Revista de Estudos Contábeis, v. 6, n. 11, p. 23-45, 2017.

PARSONS, S.; DAVIDOWITZ, B.; MAUGHAN, P. Developing professional competence in accounting graduates: An action research study. South African Journal of Accounting Research, v. 1, n. 1, p. 161-181, 2020.

PEREIRA, J. T. O papel do contador no processo de desenvolvimento e crescimento brasileiro. Revista Científica Multidisciplinar Núcleo do Conhecimento, v. 1, n. 4, p. 674686, 2017.

REIS, A. O.; SEDIYAMA, G. A. S.; MOREIRA, V. S.; MOREIRA, C. C. Perfil do profissional contábil: Habilidades, competências e imagem simbólica. Revista Contemporânea de Contabilidade, v. 12, n. 25, p. 95-116, 2015.

Revista Eletrônica do Alto Vale do Itajaí - REAVI, v.10, nº 16, p. 001-017, ago. 2021. 
SILVA, M.; SILVA, A. P. F. Perfil dos profissionais de contabilidade demandado pelo mercado de trabalho no Brasil. Revista Eletrônica de Ciências, v. 11, n. 1, p. 183-203, 2018.

SILVA, P. R. A.; NASCIMENTO, Í. C. S.; MIRANDA, M. C.; MELO, G. C. V.; SILVA, S. L. P. A contabilidade como ferramenta de auxílio às finanças pessoais: Perspectiva dos discentes de Ciências Contábeis. Revista Gestão e Organizações, v. 5, n. 2, p. 89-114, 2020.

SILVA, R. A. C. História da escola brasileira de contabilidade até o surgimento da primeira doutrina contábil positiva. In: CONGRESSO DOS TÉCNICOS OFICIAIS DE CONTAS, 5, 2015, Lisboa/Portugal. Anais [...]. Lisboa: OTOC, 2015.

SILVEIRA, J. S.; KAMIMURA, A. M.; GOMES, D. C. M.; SLOMSKI, V. G. Competências profissionais requeridas e exigidas no exame de certificação da profissão contábil. Revista Liceu On-Line, v. 9, n. 1, p. 109-133, 2019.

SOUZA, M. F.; PINTO, L. G.; BORGES, A. F. S.; SANTOS, I. D. M.; SOUZA, A. V. N. Um estudo sobre a importância do profissional de contabilidade para o crescimento de pequenas empresas. In: CONGRESSO DE GESTÃO, NEGÓCIOS E TECNOLOGIA DA INFORMAÇÃO, 2, 2018, Aracaju/SE. Anais [...]. Aracaju: UNIT, 2018.

WOLLINGER, H.; MARTINS, Z. B.; MARINHO, S. V. Relação entre estilos de aprendizagem e a percepção das competências adquiridas: Um estudo com discentes do curso de graduação em Ciências Contábeis. In: ENCONTRO DA ANPAD, 42, 2018, Curitiba/PR. Anais [...]. Rio de Janeiro: ANPAD, 2018.

YANTO, H.; FAM, S. F.; BAROROH, N.; JATI, K. W. Graduates' accounting competencies in global business: Perceptions of indonesian practitioners and academics. Academy of Accounting and Financial Studies Journal, v. 22, n. 3, p. 1-17, 2018.

Revista Eletrônica do Alto Vale do Itajaí - REAVI, v.10, nº 16, p. 001-017, ago. 2021. 